ISSN 0103-989X

Licenciado sob uma Licença Creative Commons

(c) (1) ()

\title{
Perfil de consumo e percepção da qualidade da carne suína por estudantes de nível médio da cidade de Irati, PR
}

\author{
Consumption and quality perception of pork meat by high school students \\ of the city of Irati, PR
}

\author{
Elise Thoms ${ }^{[a]}$, Luciane Silvia Rossa ${ }^{[\mathrm{b}]}$, Evelyn von Rosen Stahlke ${ }^{[\mathrm{c}]}$, Isabelle Dangui Ferro ${ }^{[\mathrm{d}]}$, \\ Renata Ernlund Freitas de Macedo ${ }^{[\mathrm{e}]}$
}

[a] Médica veterinária, Setor de Qualidade do Frigorífico Thoms, Irati, PR - Brasil, e-mail: elise@thoms.com.br

[b] Médica veterinária, Mestranda em Ciência Animal pela Pontifícia Universidade Católica do Paraná (PUCPR), São José dos Pinhais, PR - Brasil, e-mail: lu.rossa@hotmail.com

[c] Médica veterinária, Mestranda em Ciência Animal pela Pontifícia Universidade Católica do Paraná (PUCPR), São José dos Pinhais, PR - Brasil, e-mail: evelyn.stahlke@gmail.com

[d] Médica veterinária, Mestranda em Ciência Animal pela Pontifícia Universidade Católica do Paraná (PUCPR), São José dos Pinhais, PR - Brasil, e-mail: fdisabelle@hotmail.com

[e] Médica veterinária, professora Doutora da Pontifícia Universidade Católica do Paraná (PUCPR), São José dos Pinhais, PR - Brasil, e-mail: renata.macedo@pucpr.br

\section{Resumo}

A carne suína possui reconhecido valor nutricional e sensorial, sendo, por isso, a espécie de carne mais consumida no mundo e a mais utilizada para a fabricação de derivados. Contudo, o consumo de carne suína no Brasil é menor que o de carne bovina e de frango, e há pouco conhecimento da população sobre suas características de qualidade. Este trabalho teve como objetivo avaliar o perfil de consumo e a percepção de atributos de qualidade das principais espécies de carne consumidas no País por estudantes da cidade de Irati, PR, com enfoque para a carne suína. A pesquisa foi realizada com 470 alunos do ensino médio de duas escolas públicas e duas escolas privadas de Irati. A avaliação foi realizada mediante formulário de 18 questões relativas à frequência, forma de consumo, preferência, razão para consumo e percepção de saúde, risco de transmissão de enfermidades e do bem-estar animal para as carnes bovina, suína e de frango. A carne bovina mostrou-se a preferida e a mais consumida pelos estudantes. A carne suína foi preferida por 33\% dos estudantes e apontada como a menos saudável (83\%), de maior risco de transmissão de enfermidades $(80 \%)$ e de menor bem estar animal na produção $(60 \%)$. O sabor foi o 
principal motivo e a forma in natura a mais frequente para o consumo de carnes. O consumo de carne suína pelos estudantes mostrou-se limitado, sendo importante o emprego de estratégias que desmistifiquem sua qualidade, especialmente aos jovens, que irão constituir o perfil do futuro consumidor de carnes no País.

Palavras-chave: Carne suína. Pesquisa de consumo. Atributos de qualidade.

\begin{abstract}
Pork meat has recognized nutritional and sensory qualities. Because of those characteristics, it is the most consumed meat and the most used in the manufacturing of meat products in the world. However, pork meat consumption in Brazil is still lower than beef and chicken and there is a lack of information on its quality by the Brazilian population. This study aimed to evaluate the consumption and the quality perception of the three main types of meat consumed in the country by high school students from public and private schools in the city of Irati, PR. The survey was conducted with 470 students from two public and two private schools. The evaluation was performed using a form with 18 questions regarding the frequency, pattern of consumption, preference, reason for consumption and perception of health, risk of food borne disease and animal welfare for beef, pork and chicken. Beef was preferred and the most consumed meat by students. Pork was preferred by $33 \%$ of the students and pointed out as the least healthy $(83 \%)$, implicates the highest risk of food borne diseases (80\%) and the lowest welfare in animal production (60\%). Taste was the main reason for meat consumption and the most frequent meat consumption form was in natura. Consumption of pork meat was shown to be low, thus it is very important the development of strategies to unveil its quality, especially to the young consumers, who will define the meat market of the future.
\end{abstract}

Keywords: Pork meat. Consumer opinion. Quality.

\title{
Introdução
}

Na última década do século XX, o consumo mundial de carne cresceu cerca de 40\%, sendo estimado para a primeira década do século XXI crescimento de 2,2\% ao ano (NGAPO; MARTIN; DRANSFIELD, 2007).

A carne suína é consumida em todos os continentes do mundo, possuindo grande importância econômica em diversos países. Embora a indústria de carne suína tenha se tornado altamente competitiva e esta seja a espécie de carne mais consumida no mundo, no Brasil seu consumo ainda é menor que o de carne bovina e de frango (LAURENTI et al., 2009).

Segundo Tramontini (2000), o consumo de carne bovina representa 49,6\% do consumo total de carnes no Brasil, seguido pelo consumo de carne de aves com 34,6\%. A carne suína compreende apenas 15,8\% do consumo total de carnes no País. O mesmo autor justifica a grande extensão territorial brasileira, que permite a produção de bovinos a baixo custo, o grande desenvolvimento da avicultura industrial, a diferenciação dos cortes de bovinos e aves, e preconceitos relacionados à carne suína como alguns dos fatores que determinam seu baixo consumo no País.

O aumento do consumo per capita é um desafio para o setor da carne suína, porque as necessidades e expectativas do consumidor contribuem significativamente para a escolha da fonte proteica. A palatabilidade e a qualidade da carne estão relacionadas com o sabor, aroma, suculência e maciez, sendo essas características de grande importância na decisão de compra pelo consumidor (MOELLER et al., 2010). Assim, além do desempenho produtivo dos animais, os produtores de carne suína devem estar atentos à qualidade intrínseca da carne para atender às expectativas do consumidor (ROSA et al., 2008).

Grunert (2006) analisou as tendências e o perfil dos consumidores de carne e identificou, entre as tendências de consumo, a consciência crescente da relação alimentação e saúde e o maior interesse quanto à origem da carne e o sistema de criação dos animais de produção.

Rev. Acad., Ciênc. Agrár. Ambient., Curitiba, v. 8, n. 4, p. 449-459, out./dez. 2010 
Com relação à carne suína, a preocupação mundial dos consumidores com a própria saúde e o bem-estar impulsionou a indústria a investir na criação de animais com menor teor de gordura corporal e, consequentemente, menor teor de colesterol e valor calórico (MAGNONI; PIMENTEL, 2007).

Em virtude das exigências do mercado, têm-se verificado, em diversos países, mudanças nos sistemas de produção de carne suína, pelo emprego de sistemas que visem ao bem-estar animal, ao cuidado com o meio ambiente e à sustentabilidade. A preocupação dos consumidores com as consequências ambientais e éticas da produção intensiva de carne tem crescido progressivamente e começa a demandar práticas agrícolas mais sustentáveis e a nortear as preferências de compra pelo consumidor (VERMEIR; VERBEKE, 2006). Neste sentido, apesar de os sistemas de produção de carne suína ainda serem muito heterogêneos, verifica-se aumento no interesse por sistemas de criação menos intensiva de suínos, nos quais os animais são criados com livre acesso ao ambiente externo e com menor impacto para o meio ambiente (NARDONE; VALFRE, 1999; RUSSELL; DIEZ-GONZALEZ; JAVIS, 2000; RINEHART, 2006; PEREZ; CASTRO; FURNOLS, 2009).

No que se refere à percepção e ao consumo da carne suína no Brasil, em pesquisa realizada pela Associação Paulista de Criadores de Suínos no início da década de 2000, verificou-se que a população brasileira considera o sabor da carne suína seu principal atributo. Contudo, 35\% desses consumidores afirmaram acreditar que a carne suína pode veicular doenças aos consumidores e 50\% deles, que contém alto teor de gordura e de colesterol. Este conceito errôneo da carne suína deve-se principalmente ao desconhecimento de grande parte da população dos intensos trabalhos de melhoria genética, nutrição, manejo e sanidade dos animais desenvolvidos pelo setor suinícola nacional ao longo das últimas décadas (ROPPA, 2005).

A melhoria da percepção dos consumidores a respeito da sanidade da carne suína será conquistada com o desenvolvimento de medidas efetivas para o controle e a garantia da segurança sanitária, como os sistemas de rastreabilidade e de divulgação dos riscos reais de consumo (ANGULO; GIL, 2007; VERBEKE et al., 2007).

Embora as preocupações com a segurança sanitária dos produtos cárneos tenham influência no comportamento dos consumidores (VERBEKE; VACKIER, 2004; McCARTHY; HENSON, 2005), alguns estudos recentes indicam que as decisões dos consumidores para a aquisição e o consumo da carne estão se tornando, gradualmente, mais influenciadas pelas questões relacionadas à nutrição e à saúde do que pela segurança alimentar (VERBEKE et al., 2007; FONSECA; SALAY, 2008).

Até a década de 1960, a suinocultura era caracterizada pela produção de suínos com altos percentuais de banha. Porém, a partir da década de 70, com o surgimento do processo de hidrogenação na industrialização do óleo vegetal, a produção de banha perdeu valor comercial pela queda no consumo de gordura animal para o preparo e conservação dos alimentos.

Desta forma, por motivos econômicos, os suinocultores passaram a criar animais com menor percentual de gordura, que atinge, nos modelos atuais de produção de suínos, percentual semelhante ao das carnes bovina e ovina. Apesar disso, muitos consumidores ainda associam a carne suína ao elevado teor de gordura (HENKIN, 2002). Por outro lado, em países como a China, onde a carne suína é a preferida da população, verifica-se pouco esforço dos produtores em aumentar o teor de carne magra na carcaça, visto que nesse local a quantidade de gordura está diretamente relacionada à qualidade sensorial da carne (IRGANG, 2008).

A demanda por qualquer produto alimentício deve-se, principalmente, ao desenvolvimento de estratégias que popularizem seu consumo. Nesse sentido, é imprescindível o conhecimento das preferências e das necessidades do consumidor mediante pesquisas de mercado, as quais são também uma forma de reduzir os riscos de investimento, minimizar erros de planejamento e marketing e estabelecer estratégias de gestão (FARIA et al., 2006).

Este trabalho foi realizado tendo em vista a importância de conhecimento do perfil e das preferências do consumidor para impulsionar o consumo de carne suína no Brasil e o fato de que os atuais adolescentes serão os futuros formadores de opinião para o consumo desse tipo de carne. Ele teve como objetivo avaliar o perfil de consumo e a percepção de atributos de qualidade das principais espécies de carne consumidas no País por estudantes do ensino médio da rede pública e privada da cidade de Irati, PR, tendo como foco principal a carne suína.

Rev. Acad., Ciênc. Agrár. Ambient., Curitiba, v. 8, n. 4, p. 449-459, out./dez. 2010 


\section{Material e métodos}

\section{População estudada}

A pesquisa de campo foi realizada durante o segundo semestre de 2009 com estudantes em quatro escolas do município de Irati, localizado na região centro-sul do Estado do Paraná. O grupo de estudantes entrevistados pertencia à faixa etária de 15 e 17 anos e era formado por alunos matriculados da $1^{\text {a }}$ a $3^{\mathrm{a}}$ séries do ensino médio em duas escolas públicas e duas escolas privadas. Participaram da pesquisa 199 alunos de escolas privadas e 271 alunos de escolas públicas, totalizando 470 estudantes avaliados.

\section{Metodologia de pesquisa}

O perfil de consumo de carnes dos alunos foi avaliado mediante a aplicação de um formulário de questões contendo 18 perguntas fechadas relativas ao consumo das carnes bovina, suína e avícola (frango). O formulário era constituído por questões objetivas, contendo de duas a seis alternativas em cada questão, que abordaram os seguintes aspectos:

- frequência do consumo de carnes em geral e por espécie animal (bovina, suína e de frango);

- preferência e razão para o consumo da carne de cada espécie animal (bovina, suína e de frango);

- percepção sobre a espécie de carne menos saudável e sobre a possibilidade de transmissão de doenças pelo seu consumo;

- percepção sobre o bem-estar animal na produção de carne para as diferentes espécies estudadas;

- frequência de consumo da carne na forma in natura ou industrializada para as diferentes espécies animais.

Previamente à aplicação do questionário, os alunos foram informados sobre o objetivo da pesquisa e o tempo necessário para sua realização, sendo a pesquisa realizada com a ciência e o consentimento deles.

No sentido de permitir aos pesquisadores minimizar erros de interpretação, avaliar a eficiência do questionário e identificar suas dificuldades de aplicação, um questionário preliminar foi apresentado a um grupo pequeno de alunos. Os resultados deste teste preliminar foram utilizados para ajustes de linguagem, visando à facilidade de entendimento dos alunos e à obtenção de resultados mais fidedignos na aplicação do questionário definitivo.

Os resultados obtidos foram analisados estatisticamente e expressos em porcentagem. Os resultados de algumas questões de maior relevância foram submetidos ao teste de qui-quadrado $\left(\chi^{2}\right)$ para verificação de diferença entre as respostas dos alunos de escolas públicas e dos alunos das escolas privadas, adotando-se o nível de significância $\mathrm{p}=0,05$ (CALLEGARI-JACQUES, 2003).

\section{Resultados e discussão}

Em pesquisa citada por Tonini (2009), a carne e seus derivados foram apontados como a última categoria de alimentos a ser excluída da dieta alimentar pela população brasileira, independentemente da classe social, em caso de contenção de custos graças a um cenário econômico adverso. A mesma pesquisa ainda apontou que a opção pelo tipo de carne sofre influência direta do seu custo em momentos de restrição econômica.

No presente estudo verificou-se que $75 \%$ dos estudantes avaliados afirmaram consumir carne nas refeições em praticamente todos os dias da semana, sendo que 7\% afirmaram consumir uma única vez na semana e $2 \%$ não consumir esse tipo de alimento. Contudo, quando questionados sobre o consumo semanal de carne suína, apenas 15\% dos estudantes relataram consumi-la mais de uma vez por semana, 26\% uma vez por semana, $16 \%$ uma vez por mês e 17\% afirmaram não consumir carne suína, como apresentado na Figura 1.

Rev. Acad., Ciênc. Agrár. Ambient., Curitiba, v. 8, n. 4, p. 449-459, out./dez. 2010 


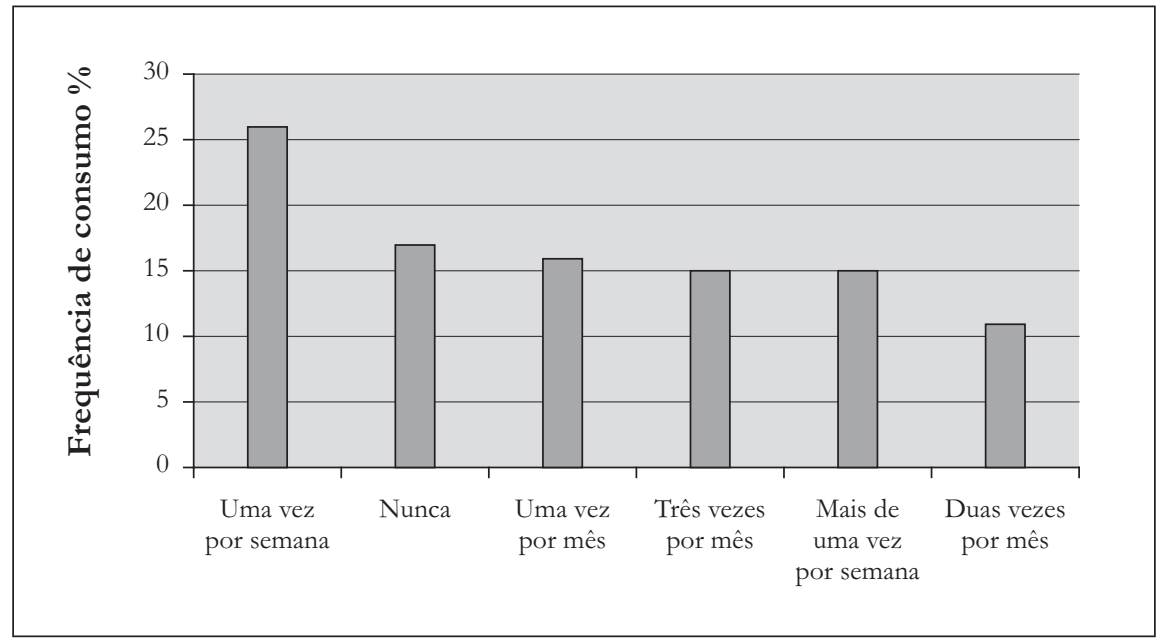

Figura 1 - Frequência de consumo da carne suína por estudantes do ensino médio da cidade de Irati, PR

Fonte: Dados da pesquisa.

Os dados obtidos para o consumo de carne suína diferem dos resultados obtidos por Dalla Costa et al. (2007) em pesquisa com estudantes do ensino médio da cidade de Toledo, PR, na qual 12,8\% dos entrevistados afirmaram consumir carne suína diariamente e 52,4\%, semanalmente.

Dos alunos que informaram consumir carne suína uma vez por semana, 29,52\% pertenciam às escolas públicas e $21,10 \%$ às escolas privadas, havendo diferença significativa de $5 \%$ para essa questão entre os estudantes das escolas públicas e das escolas privadas.

Poletto Santos Filho e Barni (2002) avaliaram o consumo da carne suína nos Estados de São Paulo, Paraná, Santa Catarina e Rio Grande do Sul e constataram que, entre os entrevistados consumidores de carne suína diariamente, 5,2\% eram de Santa Catarina, 2,5\% do Rio Grande do Sul, 1,9\% de São Paulo e 1\% do Paraná.

Para a frequência de consumo das carnes bovina e de frango, verificou-se que $62 \%$ dos alunos estudantes informaram consumir carne bovina com frequência superior a uma vez na semana e somente 4\% informaram consumo uma vez ao mês. Para a carne de frango, 37\% dos alunos afirmaram consumi-la com frequência superior a uma vez na semana e $8 \%$ afirmaram consumi-la uma vez ao mês.

No que se refere à espécie de carne mais consumida, verificou-se a preferência dos estudantes pela carne bovina (50\%), seguida pela carne de frango (33\%). A carne suína foi preferida por somente $17 \%$ dos estudantes (Tabela 1). Entre os estudantes que afirmaram preferir a carne suína às demais espécies, os alunos das escolas públicas mostraram maior preferência (16,60\%), com diferença significativa para os alunos de escolas privadas $(6,03 \%)$.

Bezerra et al. (2007) também verificaram a preferência de consumidores de Campina Grande, PB, pela carne bovina $(47,75 \%)$, seguida pela carne de frango $(21,75 \%)$. A carne suína foi apontada como preferida por somente $17,5 \%$ dos entrevistados no estudo realizado pelos autores citados anteriormente. Dados de pesquisa com consumidores que mostram a carne suína como menos apreciada que a carne bovina e a de frango também foram obtidos por Faria et al. (2006), em estudo realizado na cidade de Belo Horizonte, MG, que observaram preferência de 35,4\% dos consumidores pela carne de frango, 35,4\% pela carne bovina e apenas $26,7 \%$ pela carne suína.

A carne suína ocupa a terceira posição entre as carnes mais consumidas no País, (TRAMONTINI, 2000; UM MERCADO..., 2009) e segundo Santos Filho e Bertol (2007), o consumo de carne suína não é homogêneo em todo o Brasil, sendo os Estados do Norte os que menos consomem e os Estados do Sul os maiores consumidores. Na região Sudeste, o Estado de Minas Gerais destaca-se como grande consumidor deste tipo de carne.

Rev. Acad., Ciênc. Agrár. Ambient., Curitiba, v. 8, n. 4, p. 449-459, out./dez. 2010 
Tabela 1 - Preferência e percepção dos estudantes do ensino médio da cidade de Irati, PR em relação às carnes suína, bovina e de frango

\begin{tabular}{lccc}
\hline & \multicolumn{2}{c}{ Espécies de carne } \\
\cline { 2 - 4 } Preferência e percepção dos estudantes & Suíno & Bovino & Frango \\
\hline Preferência (\%) & 33 & 50 & 17 \\
Percepção de carne menos saudável (\%) & 83 & 10 & 7 \\
Percepção de maior risco de transmissão de enfermidades (\%) & 80 & 10 & 10 \\
Percepção de menor conforto na produção e abate dos animais (\%) & 60 & 14 & 26 \\
\hline
\end{tabular}

Fonte: Dados da pesquisa.

Em pesquisa sobre o consumo de carne suína realizada em três grandes capitais do Sul e Sudeste do País no ano 2000, São Paulo, Curitiba e Porto Alegre, verificou-se que o maior consumo concentrou-se na cidade de Curitiba, onde $71,8 \%$ dos entrevistados afirmaram consumir carne suína. Observou-se também que $34,77 \%$ do total de entrevistados informaram não consumir carne suína (SANTOS FILHO; BERTOL, 2007).

Apesar da posição da carne suína na preferência do consumidor brasileiro, essa é a mais consumida no mundo, representando 39\% do consumo mundial e superando com folga a carne de frango, com $30 \%$ do consumo mundial e a carne bovina, com 24\% do consumo mundial (UM MERCADO..., 2009). A despeito dos dados mundiais de consumo de carne suína e da modernização de sua produção nas últimas décadas, ainda se observa preconceito em relação ao seu consumo. Isso se deve não somente a fatores culturais e religiosos, mas também ao desconhecimento técnico dos consumidores que gera mitos, afetando diretamente o consumo de carne suína (LOBATO, 2008).

Quando questionados sobre o motivo de preferência por determinada espécie de carne, os alunos entrevistados informaram que o sabor das carnes era o atributo mais influente $(66 \%)$. As alternativas que se referiam à facilidade de preparo e ao custo das carnes foram apontadas por $22 \%$ e $7 \%$ dos estudantes, respectivamente.

A constatação de que o custo não foi apontado pelos estudantes como um fator determinante para o consumo de carnes pode estar relacionada ao fato de que a maioria dos alunos não possui como responsabilidade a aquisição dos alimentos ou a preparação das refeições em seus lares. Bezerra et al. (2007) observaram que 39,5\% dos adultos entrevistados em Campina Grande afirmaram escolher o tipo de carne para consumo em virtude do custo, $28,5 \%$ pelo sabor, $22,75 \%$ pela aparência e 9,25\% pelo valor nutritivo.

Para a carne suína, o principal motivo apontado pelos estudantes para seu consumo estava relacionado ao sabor (65\% das respostas). A facilidade de preparo e o custo de aquisição da carne suína foram apontados como principal motivo de preferência por 19\% e 13\% dos alunos, respectivamente. Ainda que o sabor da carne suína seja preferido por uma parcela da população brasileira, a carne bovina ainda é consumida em maior quantidade (LOBATO, 2008).

Faria et al. (2006) constataram que os fatores decisivos para a escolha do consumidor na aquisição da carne in natura foram aparência (44,4\%), sabor $(28,2 \%)$, custo $(13,7 \%)$ e frescor do produto (12,5\%). Esses autores ainda verificaram que a carne suína era a mais consumida pela população com renda mensal inferior a três salários mínimos em pesquisa com consumidores da cidade de Belo Horizonte.

No que se refere à percepção de promoção de saúde relacionada ao consumo de carne pelos estudantes, verificou-se que $83 \%$ dos alunos apontaram a carne suína como menos saudável do que as carnes bovina e de frango (Tabela 1). A carne de frango foi percebida como a mais saudável pelos estudantes (93\%). Esse resultado também foi obtido por Fonseca e Salay (2008). Faria et al. (2006) verificaram que a carne de aves foi considerada a mais saudável por 70,8\% das pessoas entrevistadas, a carne bovina por 19\% e a carne suína por somente $6,2 \%$ dos entrevistados em Belo Horizonte. Na avaliação das respostas dos alunos, de acordo com

Rev. Acad., Ciênc. Agrár. Ambient., Curitiba, v. 8, n. 4, p. 449-459, out./dez. 2010 
a escola a que pertenciam, $80 \%$ dos oriundos de escolas privadas e 74,9\% dos de escolas públicas afirmaram crer que a carne de frango é mais saudável do que as carnes suína e bovina.

Santos Filho e Bertol (2007) verificaram resultados semelhantes em pesquisa com consumidores de diferentes atividades profissionais, entre os quais $84 \%$ dos aposentados, $51,5 \%$ dos profissionais da saúde e $51,7 \%$ dos educadores entrevistados afirmaram não consumir carne suína por acreditarem ser prejudicial à saúde e estar associada a doenças cardiovasculares.

$\mathrm{Na}$ cidade de Campina Grande, Bezerra et al. (2007) observaram que 51,75\% dos consumidores avaliados afirmaram crer que a carne suína possui maior teor de colesterol quando comparada à carne bovina ou de frango.

Embora a maioria dos consumidores acredite que a carne suína possua menor qualidade nutricional do que as carnes bovina e de frango, dados científicos mostram que a carne suína é rica em proteínas e fonte importante de vitaminas $\mathrm{B}_{1}, \mathrm{~B}_{2}, \mathrm{~B}_{6}, \mathrm{~B}_{12}$ e $\mathrm{A}$, possuindo ainda baixo valor energético, em torno de $147 \mathrm{kcal} / 100 \mathrm{~g}$ (BRAGAGNOLO; RODRIGUEZ-AMAYA, 2002).

Em comparação com a carne bovina, a carne suína apresenta maior teor de aminoácidos essenciais, como leucina, lisina e valina (MAGNONI; PIMENTEL, 2007).

Assim como nas outras carnes, estima-se que 40\% do conteúdo total de ferro da carne suína está na forma heme, cuja absorção pelo organismo é mais eficiente. Além disso, alguns cortes suínos apresentam maior quantidade total de ferro em relação às aves e aos pescados (MAGNONI; PIMENTEL, 2007).

A carne suína magra possui 34\% menos colesterol do que a carne de frango sem pele e o lombo suíno possui menos calorias do que o filé mignon bovino, corte considerado por muitos consumidores como referência de carne magra (SILVA, 1995; STEWART; KAPLAN; BEITZ, 2001).

Adicionalmente ao baixo teor de gorduras saturadas e de colesterol, a carne suína contém menor teor de sódio que as demais carnes e maior teor de potássio (MAGNONI; PIMENTEL, 2007). Cerca de 70\% da gordura do suíno localiza-se abaixo da pele e não entre as fibras musculares, o que a torna menos prejudicial à saúde do consumidor (SILVA, 1995).

Fonseca e Salay (2008), em pesquisa com consumidores de carne realizada na cidade de Campinas, SP, verificaram que os atributos relacionados à composição nutricional da carne suína, como o teor de gordura, colesterol e o valor calórico mostraram maior influência sobre a intenção de consumo do que os atributos relacionados à segurança sanitária. Esse resultado deve-se provavelmente ao fato de que o consumo de alimentos com altos níveis de colesterol tem sido condenado pela maioria dos médicos e de que a maior parte da população ainda crê que a carne suína possui alto teor de colesterol, o que gera repulsa a seu consumo.

Ludke e López (1999) afirmam que o teor de colesterol sanguíneo advindo da dieta é influenciado pelo tipo de gordura ingerida, que pode ser monoinsaturada, poliinsaturada ou saturada, e que a ingestão de ácidos graxos insaturados da família ômega está associada à redução do colesterol sanguíneo. O ácido linoleico, um dos representantes da família ômega, está presente em grandes concentrações nas carnes. A carne suína é uma das que possui os maiores teores desse ácido graxo $(35,1 \%)$ em relação às carnes bovina $(10,5 \%)$, ovina $(18,5 \%)$, de frango $(14,2 \%)$ e de peixes $(5,8 \%)$ (GONÇALVES, 2008).

No momento da aquisição da carne suína, a quantidade de gordura visível é o mais forte estímulo discriminativo no processo de escolha (BREWER; ZHU; McKEITH, 2001). Sendo assim, a aparência do produto é um fator muito importante a ser considerado neste momento (VERBEKE et al., 2005) e este fato poderia explicar o baixo consumo de carne suína pela população brasileira.

Segundo Meinert et al. (2008), a demanda mundial dos consumidores tem sido por carnes com baixo conteúdo de gordura e, com vistas a esse perfil de consumidor, nas últimas décadas a produção de carne suína tem sido focada na diminuição do teor de gordura.

No Brasil, a suinocultura é caracterizada pela produção tecnificada e realizada por grandes agroindústrias. Esta característica proporcionou o aumento da produção e a melhoria das condições de sanidade desde a criação dos animais até a obtenção do produto final (MOREIRA et al., 2007).

Apesar da tecnologia e do controle sanitário empregados na produção da carne suína, ela foi apontada por $80 \%$ dos estudantes entrevistados como a de maior risco de transmissão de enfermidades aos humanos, enquanto somente $10 \%$ dos alunos apontaram a carne bovina ou a carne de frango nesta questão.

Rev. Acad., Ciênc. Agrár. Ambient., Curitiba, v. 8, n. 4, p. 449-459, out./dez. 2010 
Entre os estudantes avaliados, 94\% acreditavam que a carne, de modo geral, pode atuar como carreadora de enfermidades aos consumidores. Entre os alunos informantes que a carne de frango está menos associada à transmissão de enfermidades aos humanos, $58,29 \%$ pertencia às escolas privadas e $56,82 \%$ às escolas públicas.

Estes dados mostram que, apesar da modernização na criação de suínos, ainda se observa preconceito em relação à carne suína, não somente por fatores culturais e religiosos, mas também pela falta de conhecimento, o que influencia diretamente seu consumo (LOBATO, 2008).

Outra questão atualmente relevante para o setor de produção de carne refere-se ao bem-estar animal. Vários são os indicativos de que o bem-estar animal é uma exigência mundial para os sistemas industriais de produção animal. Desta forma, além das preocupações relacionadas à sanidade, nutrição e melhoramento genético dos animais, há crescente interesse da população pelo conforto e pelas condições de manejo dos animais de abate. Neste trabalho, a maioria dos alunos entrevistados $(60 \%)$ afirmou crer que os suínos são criados e abatidos em piores condições de conforto do que os frangos (26\%) e os bovinos (14\%) (Tabela 1). No entanto, os avanços tecnológicos na produção de carne suína também trouxeram melhorias no ambiente e nas condições de criação, transporte e abate desses animais de maneira a contemplar os aspectos referentes ao bem-estar animal (BRAUN, 2001).

Dos alunos que afirmaram acreditar que os bovinos são criados e abatidos em melhores condições de bem-estar do que as demais espécies citadas, 54,77\% pertenciam às escolas privadas e 46,49\% às escolas públicas, havendo diferença significativa entre as repostas para o tipo de estabelecimento de ensino.

Os alunos também foram questionados quanto à forma de apresentação para consumo das carnes, in natura ou em produtos derivados. Para as três espécies de carne avaliadas, bovina, suína e de frango, os alunos informaram maior consumo na forma in natura, sendo $84 \%$ para a carne bovina, $77 \%$ para a carne de frango e $63 \%$ para a carne suína. A carne suína foi indicada como a de maior consumo na forma industrializada (32\%).

Dados da Associação Brasileira de Indústria Produtora e Exportadora de Carne Suína (Abipecs) indicam que dos $13 \mathrm{~kg}$ de carne suína consumidos por pessoa ao ano no País, aproximadamente $10 \mathrm{~kg}$ são representados por produtos industrializados e embutidos, como presunto, apresuntado, salsicha, salame, cortes cozidos e temperados entre outros (UM MERCADO..., 2009).

Faria et al. (2006) verificaram que apesar do consumo de carne suína ser menor do que o de carne bovina e de frango, a maioria da população entrevistada na cidade de Belo Horizonte consome produtos derivados de carne suína semanalmente, sendo que desses, $29,2 \%$ os consomem de duas a três vezes por semana, $24,2 \%$ uma vez por semana e 17\% diariamente. A grande variedade de produtos elaborados com carne suína, representados pelos embutidos, defumados, pré-cozidos e produtos semiprontos, de diferentes marcas e níveis de preço, faz com que esses produtos atinjam consumidores de todas as classes socioeconômicas e com que a carne suína, de alguma forma, sempre esteja presente à mesa do consumidor brasileiro.

Dos consumidores dos Estados do Sul e Sudeste brasileiros, o consumo diário de derivados suínos defumados e frescais como bacon e linguiça mostrou-se maior no Estado de São Paulo (10,9\% dos consumidores), seguido por Santa Catarina (5,2\%), Rio Grande do Sul (4,9\%) e Paraná (4\%) (POLETTO et al., 2002). Para os produtos classificados como produtos "lanche", como apresuntado e salame, o consumo diário foi apontado por 18,4\% dos consumidores do Rio Grande do Sul, 17,9\% em Santa Catarina, 14,4\% em São Paulo e 5,2\% no Paraná. Esses resultados mostraram que entre os Estados pesquisados, o Estado do Paraná foi o que apresentou o menor consumo de derivados de carne suína.

\section{Conclusão}

Entre os estudantes de ensino médio das escolas públicas e privadas avaliados, $75 \%$ afirmaram consumir carne diariamente, sendo o consumo diário de carne bovina apontado por $64 \%$ dos estudantes. Contudo, para a carne suína, somente $15 \%$ dos estudantes informaram consumi-la diariamente. Entre as carnes suína, bovina e de frango, a carne suína foi apontada como preferida por 33\% dos estudantes, havendo diferença significativa para essa preferência entre os estudantes de escolas públicas e privadas, que mostraram preferência significativamente inferior à dos alunos das escolas públicas. Os alunos também afirmaram acreditar

Rev. Acad., Ciênc. Agrár. Ambient., Curitiba, v. 8, n. 4, p. 449-459, out./dez. 2010 
que a carne suína seja menos saudável (83\% das respostas) e que apresenta o maior risco de transmissão de enfermidades aos consumidores ( $80 \%$ das respostas) em comparação às carnes bovina e de frango. O sabor foi o principal motivo apontado pelos alunos para a preferência por determinada espécie de carne, superando o custo de aquisição e a facilidade de preparo. A forma in natura foi apontada como a forma mais frequente de consumo de carne pelos alunos, para as três espécies animais avaliadas.

O consumo de carne suína ainda se mostra limitado graças a crenças e ao desconhecimento dos estudantes sobre sua qualidade nutricional e sensorial e da tecnologia empregada em sua produção. Neste sentido, a indústria de carne suína deve desenvolver estratégias de informação e esclarecimento aos consumidores, especialmente aos jovens, que definirão o perfil do futuro consumidor brasileiro de carnes.

\section{Referências}

ANGULO, A. M.; GIL, M. Risk perception and consumer willingness to pay for certified beef in Spain. Food Quality and Preference, v. 18, n. 8, p. 1106-1117, 2007.

BEZERRA, J. M. M. et al. Caracterização do consumidor e do mercado da carne suína na microrregião de Campina Grande, estado da Paraíba. Ciência Animal Brasileira, v. 8, n. 3, p. 485-493, 2007.

BRAGAGNOLO, N.; RODRIGUEZ-AMAYA, D. B. Teores de colesterol, lipídios totais e ácidos graxos em cortes de carne suína. Ciência e Tecnologia de Alimentos, v. 22, n. 1, p. 98-104, 2002.

BRAUN, J. A. O bem-estar animal na suinocultura. In: CONFERÊNCIA INTERNACIONAL VIRTUAL SOBRE QUALIDADE DE CARNE SUÍNA, 1., 2000, Concórdia. Anais... Concórdia: Embrapa Suínos e Aves, 2001. p. 1-3.

BREWER, M. S.; ZHU, L. G.; McKEITH, F. K. Marbling effects on quality characteristics of pork loin chops: consumer purchase intent, visual and sensory characteristics. Meat Science, v. 59, n. 2, p. 153-163, 2001.

CALLEGARI-JACQUES, S. M. Bioestatística, princípios e aplicações. Porto Alegre: Artmed, 2003.

DALLA COSTA, M. C.; CORDONI Jr., L.; MATSUO, T. Hábito alimentar de escolares adolescentes de um município do Oeste do Paraná. Revista de Nutrição, v. 20, n. 5, p. 461-471, 2007.

FARIA, I. G.; FERREIRA, J. M.; GARCIA, S. K. Mercado consumidor de carne suína e derivados em Belo Horizonte. Arquivo Brasileiro de Medicina Veterinária e Zootecnia, v. 58, n. 2, p. 251-256, 2006.

FONSECA, M. C. P.; SALAY, E. Beef, chicken and pork consumption and consumer safety and nutritional concerns in the City of Campinas, Brazil. Food Control, v. 19, n. 11, p. 1051-1058, 2008.

GONÇALVES, J. R. Composição de ácidos graxos em carnes. Revista Nacional da Carne, ano 32, n. 379, p. 183-189, 2008.

GRUNERT, K. G. Future trends and consumer lifestyles with regard to meat consumption. Meat Science, v. 74, p. 149-160, 2006.

HENKIN, P. Conexão entre o consumo de carne suína e doença cardiovascular: mito ou realidade? In: CONFERÊNCIA INTERNACIONAL VIRTUAL SOBRE QUALIDADE DE CARNE SUÍNA, 2., 2001, Concórdia. Anais... Concórdia: Embrapa Suínos e Aves, 2002. p. 33-36.

IRGANG, R. Melhoramento da qualidade da carne suína. In: SIMPÓSIO BRASILEIRO DE MELHORAMENTO ANIMAL, 7., 2008, São Carlos. Anais... São Carlos: SBMA, 2008. Disponível em: <http://sbmaonline.org.br/anais/ vii/palestras/pdfs/palestra14.pdf>. Acesso em: 25 jul. 2010.

LAURENTI, E. et al. Impacto das anomalias suínas na indústria. Revista Nacional da Carne. São Paulo, ano 33, n. 384, p. 20-32, 2009.

LOBATO, J. C. V. A cisticercose e o consumo da carne suína. 2008. 35 f. Monografia (Especialização em Higiene e Inspeção de Alimentos de Origem Animal) - Universidade Castelo Branco, Vitória, 2008.

Rev. Acad., Ciênc. Agrár. Ambient., Curitiba, v. 8, n. 4, p. 449-459, out./dez. 2010 
LUDKE, M. C. M. M.; LÓPEZ, J. Colesterol e composição dos ácidos graxos na dieta para humanos e na carcaça suína. Ciência Rural, v. 29, n. 1, p. 181-187, 1999.

MAGNONI, D.; PIMENTEL, I. A importância da carne suína na nutrição humana. São Paulo: UNIFEST, 2007.

McCARTHY, M.; HENSON, S. Perceived risk and risk reduction strategies in the choice of beef by Irish consumers, Food Quality and Preference, v. 16, p. 435-445, 2005.

MEINERT, L. et al. Eating quality of pork from pure breeds and DLY studied by focus group research and meat quality analyses. Meat Science, v. 80, n. 2, p. 304-314, 2008.

MOELLER, S. J. et al. Consumer perceptions of pork eating quality as affected by pork quality attributes and end-point cooked temperature. Meat Science, v. 84, n. 1, p. 14-22, 2010.

MOREIRA, M. D.; ROCHA, V. R.; ALMEIDA, L. P. Principais patologias de suínos encontradas em matadouro frigorífico exportador do Triângulo Mineiro. Revista Higiene Alimentar, v. 21, n. 150, p. 18, 2007.

NARDONE, A.; VALFRE, F. Effects of changing production methods on quality of meat, milk on eggs. Livestock Production Science, v. 59, n. 2/3, p. 165-182, 1999.

NGAPO, T. M.; MARTIN, J. F.; DRANSFIELD, E. International preferences for pork appearance: I. Consumer choices. Food Quality and Preference, v. 18, n. 1, p. 26-36, 2007.

PEREZ, C.; CASTRO, R.; FURNOLS, M. F. The pork industry: a supply chain perspective. British Food Journal, v. 111, n. 3, p. 257-274, 2009.

POLETTO, A. R.; SANTOS FILHO, J. I.; BARNI, E. J. Avaliação do potencial de mercado dos produtos industrializados derivados de suíno. In: CONFERÊNCIA INTERNACIONAL VIRTUAL SOBRE QUALIDADE DE CARNE SUÍNA, 2., 2001, Concórdia. Anais... Concórdia: Embrapa Suínos e Aves, p. 1-28. 2002.

UM MERCADO promissor. Revista Nacional da Carne, ano 33, n. 389, p. 37, 2009.

RINEHART, L. Cattle production: considerations for pasture-based beef and dairy producers. National Sustainable Agriculture Information Service (ATTRA), 2006. Disponível em: < http://www.attra.ncat.org/attra-pub/PDF/ cattleprod.pdf>. Acesso em: 22 maio 2010.

ROPPA, L. Suinocultura mundial: situação atual e perspectivas. Pork World, v. 4, n. 25, 2005.

ROSA, A. F. et al. Qualidade da carne de suínos de três linhagens genéticas comerciais em diferentes pesos de abate. Ciência Rural, v. 38, n. 5, p. 1394-1401, 2008.

RUSSELL, J. B.; DIEZ-GONZALEZ, F.; JARVIS, G. N. Potential effect on cattle diets and the transmission of pathogenic Escherichia coli to humans. Microbes and Infection, v. 2, p. 45-53, 2000.

SANTOS FILHO, J. I.; BERTOL, T. M. Efeitos da percepção dos atributos dos alimentos e das características dos consumidores sobre o consumo de carne suína. In: CONGRESSO DA SOCIEDADE BRASILEIRA DE ECONOMIA, ADMINISTRAÇÃOE SOCIOLOGIA RURAL, 45., 2007, Londrina. Anais... Brasília: Sociedade Brasileira de Economia, Administração e Sociologia Rural, 2007. p. 1-19.

SILVA, G. J. C. Colesterol: O mito do colesterol e doenças coronarianas em poedeiras e no homem. Avicultura Ciência \& Tecnologia, ano 3, n. 15, p. 2-4, 1995.

STEWART, J. D.; KAPLAN, M. L.; BEITZ, D. C. Pork with a high content of polyunsaturated fatty acids lowers LDL cholesterol in women. American Journal of Clinical Nutrition, v. 74, n. 2, p. 179-187, 2001.

TONINI, M. G. O. Carne é o último produto a ser cortado em tempos de crise. Revista Nacional da Carne, ano 33, n. 389, p. 12, 2009.

Rev. Acad., Ciênc. Agrár. Ambient., Curitiba, v. 8, n. 4, p. 449-459, out./dez. 2010 
TRAMONTINI, P. Consumo da carne suína a experiência brasileira. In: SEMINÁRIO INTERNACIONAL DE SUINOCULTURA, 5., São Paulo. Anais... Concórdia: Embrapa Suínos e Aves, 2000. p. 6-11.

VERBEKE, W.; VACKIER, I. Profile and effects of consumer involvement in fresh meat. Meat Science, v. 67, p. 159-168, 2004.

VERMEIR, I.; VERBEKE, W. Exploring the consumer "attitude behavior" gap. Journal of Agricultural and Environmental Ethics, v. 19, p. 169-194, 2006.

VERBEKE, W. et al. Role of intrinsic search cues in the formation of consumer preferences and choice for pork chops. Meat Science, v. 69, n. 2, p. 343-54, 2005.

VERBEKE, W. et al. Why consumers behave as they do with respect to food safety and risk information. Analytica Chimica Acta, v. 586, p. 2-7, 2007.

Recebido: 16/08/2010

Received: 08/16/2010

Aprovado: 28/09/2010

Approved: 09/28/2010 